\title{
If Materialism Is Not the Solution, Then What Was the Problem?
}

\author{
A Response to Harman \\ Robert Jackson
}

\begin{abstract}
A в STR AC T What follows is a cursory response to Graham Harman's article "Materialism is Not the Solution." It seeks to branch out his conception of 'form' and more specifically, 'aesthetic form' whilst expanding on Harman's principal objections to the materialist account of change, and how this may challenge the contemporary aesthetic trajectory of relational encounter: particularly Bourriaud's Relational Aesthetics (2002). Quite generally, Harman's Object Oriented Ontology might be understood through two chief aesthetic mechanisms; the contingency of counterfactuals complimented with the preliminary development of a nonmodern formalism. The latter is briefly cashed out in a philosophical juxtaposition to Greenberg and Fried's modernist principles.

KEYWORDS Formalism, Materialism, Clement Greenberg, Michael Fried, Graham Harman, Object Oriented Ontology, Relational Aesthetics, Speculative Realism
\end{abstract}

\section{Counterfactuals}

Navigating any contemporary philosophical system is hard, as it is navigating a new computing language or cityscape. No-one really knows what it can do, at least not without experimentation. Systems of thought do not operate any differently.

Object Oriented Ontology (hereby referred to as OOO) requires a good deal of navigation, and playful experimentation before it can be used as a platform for doing things with other things. Amongst many pragmatist experiments, one of the more famous OOO devices is the 'Latour Litany' (coined by fellow OOO veteran Ian Bogost), to describe Bruno Latour's strange ontographical practice of list naming: the rhetorical function of which reveals the "inherent partition between things."1 And it is a useful practice for sure: enumerating different, potentially infinite lists of things before critique can inspect their ontological validity. You don't even have to go far: door, garden, hose, plastic, neutron.

For me however, one of the more helpful aesthetic analogies (although not mentioned in his article, but shown elsewhere) is Harman's implicit endorsement of the counterfactual. The counterfactual is a curious thing, relating to or expressing what has not happened or was not the case. Taken to the extreme, they force absurd instances of carnal novelty, such as if kangaroos had no tails, they would topple over (an example suffi- 
cient for the Oxford dictionary no less). Yet, if approached from a twist of attitude, counterfactuals encapsulate the distinct realist flavour of Harman's system, generating meaning within it as well as distinguishing it from other similar 'non-human' physicalist and materialist positions. Counterfactuals not only force us to address the contingency of historical events or to speculate on such consequences: they also underscore certain problems associated with materialist, relationist and naturalist philosophies. They not only show how static objects of form withdrawn from access, but how such forms account for such contingency.

The reader might ask why this philosophical preoccupation becomes an issue for art praxis. We will get to that later on. The basic issue comes down to how both philosophy and aesthetic theory jointly account for change, and where the locus of such a change is ontologically or epistemologically understood. Moreover, this account affects different avenues of political, aesthetic, historical, technical or social change. It seems to me that $\mathrm{OOO}$ is potentially useful, not just as a latest philosophical toolbox for motivating art praxis, but (following Harman's lead) a method of revealing the inherent problems of accounting for change in materialist and relationist positions. If such positions are used to account for the change as described in art, then by itself it also changes the account. Thus, if materialism is not the solution, then what was the problem?

As Thomas Kuhn found out, ${ }^{2}$ counterfactuals are the very thing that materialism, naturalism, mathematics and especially scientism cannot abide. That physical systems of scientific or mathematical discovery and technological innovation could have been otherwise or can be otherwise, undermines a methodology to which every system of scientific knowledge must be incrementally necessary in revealing the natural order of things. Even the quantum "many-worlds theory" relies on the material knowledge to legitimate and account for such worlds. The counterfactual ceases to function if everywhere you turn, you stumble upon a natural order of inert material waiting to be formalised, or an amorphous primordial reservoir that indeterminately produces change anyway (these two reductions of form are the focus of Harman's critique throughout the article).

Perhaps then, one might hazard a proposition that $\mathrm{OOO}$ is a realist praxis of the counterfactual: but if so, what ramifications would this have on art praxis? Change in Harman's account, is only possible because forms are not always-already relational. It is the primordial fullness of each different form which remains the same, which in turn is responsible for constructing different neighbouring effects. Counterfactuals amount to the following: what happens when an autonomous object or system 
is put into a new context of other autonomous things, or alternatively what is left of a thing once its parts are taken away or substituted? The usual view would insist (misreading Kuhn) that OOO is only a relativist account of subjective change in theoretical systems. But enforcing the realist element of OOO would not only suggest that objects of scientific theory change, but also that the concealed objects, which science seeks to uncover, also change the theory.

It's important to note that such counterfactual effects are only produced because objects are different from their relations, not because of existing in a relation. In a 2013 Speculations response to Levi Bryant, Harman encapsulates this as:

Things are not different because they affect other things differently; rather, they affect other things differently because they are already different from each from other. ${ }^{3}$

This is what Harman means when a form (like Lake Michigan), can robustly withstand its fluctuating context, as opposed to the inert wholeness of determinate physical material, or the fluid wholeness of indeterminate movement. All real objects have a substantial form, which cannot be reduced to its physical or holistic basis: instead Harman's objects exist somewhere between the two.

Following Whitehead's lead, the OOO thesis does not proceed deductively, as if every new concept is progressively unlocking the next stage of truth, or continuously, as if indeterminate change is unstoppable and unfolding. OOO might work as a discontinuous enterprise: when it considers how different scenarios, different forms or even entire philosophical systems from many different scales could have been otherwise or retrieved differently. What if post-Kantian philosophy wasn't instantly taken over by German Idealism? What if Heidegger and Whitehead happened to have met by chance and had a productive conversation? What if Wittgenstein wasn't born into one of the richest families in Austria-Hungary? This is not a realism that can be uncovered or deduced, nor a realism that is accepted as it is without question (which is politically moribund) but a realism in which different things have different effects on different things.

Aesthetic counterfactuals work to OOO's advantage. This discontinuousness is important not simply for methods of meaning and making, but for implicitly alluding to the disconnection of discrete objects: which is to say, what surprising forms of change can be produced when a counterfactual is set to work? What can praxis do on the level of experimenting with formal change in itself? 


\section{Materialism(s) and Emergent Encounters}

Consider the work of the British physicist Julian Barbour. Barbour is a joint historian of science as well as active theorist, who for nearly forty years has painstakingly argued that Einstein's general theory of relativity could have been entirely different, if he didn't make Ernst Mach's version of relativity obsolete through field theory. ${ }^{4}$ Barbour advances a counterfactual thesis in which Einstein did not mistakingly reject Machian relativity, but instead developed it outright into a wholly different system of twentieth century physics, which accounted for gravitational effects, but without the need for a background external framework of motion, fields and space-time. Eschewing any sort of academic position because of the fringe nature of his theories, Barbour denies any external physical dimensions of duration or time, instead advancing a Leibniz thesis; namely, that "the world does not contain things, the world is things,"5 and moreover those things are timeless, not in a transcendent way (although that's Platonically implied) but in theoretical way.

For Barbour, dynamic change emerges from intrinsic structure of configurations of individual form, where space is the order of coexisting things and time is the succession of coexisting things. Quoting Mach, in The Science of Mechanics (1919), "[i]t is utterly beyond our power to measure the changes of things by time. Quite the contrary, time is an abstraction at which we arrive by means of the changes of things." Just as Mach considered time as an "idle metaphysical conception,"7 and Harman critiques the 'flow' of 'matter', Barbour understands time not as a movement or a flow which generates things in a semi-amorphous field, but the illusionary status of measuring configured positions of things in a monadic block universe.

As you might have noticed, Barbour's notion of a discontinuous physics bereft of duration, does not sit with well with Bennett's cosmic mass of matter-energy, producing semi-identifiable objects. Neither does it sit well with the movement of concepts in dialectical materialism, or with the recent Derridian flavour of 'radical time' in Peter Gratton ${ }^{8}$ or Martin Hägglund. ${ }^{9}$ But that's just it, there are many materialism(s) - a useful, but now overused term which can be applied to any trendy agenda, yet nearly all materialisms rely on a 'really real' invisible framework upon which everything else unfolds: this is why the 'real material' is often sidelined by numerous terms which address only one type of stuff: history, the Real, capitalism, process, dust, the social, time, field-systems, relations, praxis, context, networks, duration, embodiment, encounter and of course, the "throbbing whole." 
The extrinsic framework of relations is many, and yet, the intrinsic thing is not. More importantly why should an invisibly grounded framework account for material excess of movement? Because of its amorphous nature? What is it about this material framework, which must explain the movement and changes of things? It might be useful to actually think of materialism(s) as a productive symptom: that there are so many types, supports Harman's realist position. For if we are faced with a choice of multiple materials to choose from, then OOO starts to get its teeth in rejecting the primacy of one type of material. And that's not to reject these terms outright, but account for why they become an issue in the changes of things and of things changing.

The invisible framework of materialism(s) has surrounded contemporary art theory for a number of years now, and whilst no origin points towards its beginning (although we can probably say it's Duchamp) - we can most certainly point towards what it has opposed; namely substantial form, quality and essence.

Consider Nicolas Bourriaud's Relational Aesthetics (2002) - a text which in the last fifteen or so years, has become an influential whipping post for every twenty-first century disagreement going forward, yet the basic materialist vision of an emergent invisible framework has commandeered the stage, facilitating any discussion after Bourriaud's inevitable fallout. Bourriaud's criticism is explicitly grounded in Louis Althusser's "materialism of encounter,"11 and more broadly collective contingency, in which the form of the individual work is reduced to a materialist encounter. For when Bourriaud discusses form as a coherent unit, the artwork never has any hold of it. Forms are always subordinated to the same type of stuff:

In the materialist philosophical tradition ushered in by Epicurus and Lucretius, atoms fall in parallel formations into the void, followed by a slightly diagonal course. If one these atoms swerves off course, it "causes an encounter with the next atom and from encounter to encounter a pile-up, and the birth of the world" [...] In order to create a world, this encounter must be a lasting one [...] Form can be defined as a lasting encounter. ${ }^{12}$

Whilst admittedly Bourriaud is waxing lyrical about Epicurean metaphysics in an effort to describe the practice of contemporary art since the mid-1990s - in the context of Harman's article, this passage reveals much about the relationship between materialism and contemporary art theory. The only lasting form that really matters is the contingency of human to human relationships: the sole aesthetic focus, and the material 
basis of contemporary artistic praxis. Thus the artwork, following Liam Gillick (one of the poster artists for Bourriaud), is nothing without the keeping together of material that forms it, and the possibilities which emerge from it, as human worlds of form.

Notice that the materialist basis of relational encounter is never rejected, even in the now classic critiques of relational aesthetics by Claire Bishop $^{13}$ (who descends even further into a Laclau-Mouffe-Žižekian materialism of a divided subject) and Grant Kester. ${ }^{14}$ Even the published rejoinder of Non-Relational Aesthetics (2008) authored by Charlie Gere and Michael Corris, tried to offer some alternatives, favouring Derridian tropes of alterity, difference and deferral, advancing an aesthetics of hospitality rather than participation. ${ }^{15}$ But these criticisms only served to question the ideological motives of the subject involved, rather than the materialist support underlying such theoretical claims. Why use a materialism of encounter, rather than a realist one to philosophically justify a collective form of contingency?

Like Marx, non-human things get short shrift: Bourriaud's focus is on how subjects transform material encounters into a lasting world, rather than articulating how lasting effects originate from form itself. If materialism simply means encounter and contingency means matter, Harman is right to question why many critics, writers and theorists continue to adhere to it. One might say that the problem to which Harman alludes, is how theoretical claims must account for art's contingency: to say that it is physical matter, or a materialism of encounter and nothing else, does not address the real problems of making work. What are the types of contingent decisions, negotiations and transformations the artist makes to exhibit a work, and what types of contingencies must they surrender to facilitate the lasting form of the work, even if the goal is just to foster vague possibilities for their own sake? Why does materialism find problems of realist form questionable when compared to subjective agency?

A final note. Bourriaud curated a 2009 show called Altermodern to single-handily force a new paradigm shift within contemporary art: declaring that postmodernism had not only ended, but artists were responding to an altogether different modernist context of globalised culture. Needless to say, if someone had handed Bourriaud a copy of Bruno Latour's We Have Never Been Modern (1993), he might have saved himself a lot of bother, and Tate funding.

Which begs the question; what would a nonmodernist aesthetics look like? 


\section{Non-Modernist Aesthetics}

Consider the contemporary art-world's indirect dealings with speculative realism so far. Whether artists have been directly influenced by the proponents of OOO, actor-network theory, and new materialism or not, it certainly seems that a change has occurred concerning the understanding and exposure of the nature of reality or 'material' after years of framing it through human orientation. And that in itself is worthwhile. The artist's materials are no longer passive or inert, but are reworked and re-contextualised, to 'let loose' their inherent, dynamic creativity.

This renewed democracy of things, the sociality of objects, can be traced in a number of shows which have attempted to understand how the agency of units and 'things' shapes viewer interactions. Arguably it began with THING: New Sculptures from Los Angeles (2005) at the Hammer Museum, together with Steven Claydon's exhibition Strange Things Permit Themselves the Luxury of Occurring (2008) at the Camden Arts Centre and Material Intelligence (2009) at Cambridge's Kettle's Yard. This new sensibility towards the aesthetic imperative and agency of things is also what brought Katherine Behar and Emmy Mikelson to curate the 2011 show And Another Thing at CUNY. The curators sought to "dislodge the human from the center of discussion, to enrich the concept of being, and to open the very world itself to all things that comprise it" using the minimalist work Base 5 Aluminum Stack (2005) by Carl Andre as a starting point: a work which simply "is what it is." Since then, more and more artists are joining the cause, witnessed in Ed Atkins and Andy Holden's performance Becoming Thing (2012) at the Whitechapel (citing Bogost's ontography), as well as Mark Leckey's very recent and very popular The Universal Addressability of Dumb Things (2013) installation at Nottingham Contemporary last year. In consideration of the sheer amount of projects taking place, this list is woefully compendious.

Moreover, the theoretical literature surrounding this shift is expanding. Rikke Hansen's 2008 essay “Things vs. Objects” in Art Monthly was specifically written to address art's return to things. According to Hansen, such works concerning things have a "bearing on the way we perceive and critique the social." Similar to Bourriaud's effort, such works need the beholder's material encounter to work, but are "never determined by the subject alone," and instead "engage directly with the form of sociality that is produced by things; artworks that, momentarily, make objects stand out against the backdrop of everyday life." ${ }^{16}$ More recently, in his review of Documenta 13 in ArtForum, Daniel Birnbaum argued that there was a productive conflict between the trauma-led artworks 
focusing on human conflict and reconciliation, and artworks which explicitly focused on the thingliness of actants and objects (or as its chief curator Carolyn Christov-Bakargiev attests: "[t]his vision is shared with, and recognizes, the shapes and practices of knowing all the animate and inanimate makers of the world, including people." $)^{17}$ Recent events and exhibitions in Dublin, associated with the National College of Art and Design (NCAD) have completely focused on foregrounded speculative realist issues in art, as evidenced in the collective Dublin Unit of Speculative Thought (D.U.S.T) producing multiple conferences and renegade exhibitions on the relationship between philosophy and art.

This is all fine in one sense: yet, perhaps a more fundamental link with Harman's realism in particular and speculative realism in general, should avoid assumptions which take the reality of objects in art discourse too literally. By this, I mean that artistic self-criticality operates as an exercise in combining an OOO text, with conventional aesthetic mediums: as if any encountered, re-contextualised, or re-focused minimal object or unit of matter is worth exhibiting in a gallery because it can perform its own 'thingly' stage theatrics as such. Note here the difference between taking the reality of the thing literally and taking the reality of the thing seriously. They are not the same 'thing'. Any difference here means highlighting the spectator's account of his or her sincerity and their implication with a form that is intrinsically deeper: not undercutting it with literal material.

In light of Harman's final remarks concerning the performative structure of aesthetic imitation in the beholder, viewer or spectator, I think an interesting dialogue can be opened up about how certain anti-literalist artistic practices might correspond to the investment of sincerity he speaks of.

This is why I find Harman's Greenbergian influence so potent, particularly since the unbelievable fallout of artists in late 6os and 70s, were all united in rejecting his peculiar brand of formalism. What happens if you foster a new formalist aesthetic of hidden internal complexity but remove the teleological holistic pangs of modernism, intentionality and self-mastery from it? The problem is Greenberg never bothered to distinguish formalism from modernism, and even if he did, his formalism would never have corresponded to substantial form in the way that a realist ontology supposes.

Harman notes that Greenberg's dual historical problem fosters unanswered questions concerning different guiding principles of contemporary art since Pollock. One might suggest then, that it was Michael Fried, Greenberg's protégé, who asked a similar question: and as direct 
result rejected Greenberg's view that modernist painting must have an unchanging essence, carefully stripping away the medium towards a predetermined purity. ${ }^{18}$ For him, such a position led down a "cul-de-sac artistically and theoretically"19 (for instance, how could anything new emerge in foregrounded content if its formal, backgrounded essence remains fundamentally unchanged).

Fried believed that the authentic way to think of essence was historical: high modernism was of the opinion that the self-criticality of a medium only changed within its own individual formal conventions and of social consensus. Thus, the acknowledgement of that break (in Fried and Cavellian terms) would be essential to the medium in question, in light of modernity's previous quality. Moreover, all of its content would be constantly subject to revision. What is revealed in the content is not the irreducible essence of all painting, such that it follows a linear path, but of breaking conventions through the medium's convention itself. By doing so, quality would come from the intrinsic capabilities of the medium, in comparison to its inherited modernist and premodernist past, and that such conviction was without question. ${ }^{20}$

In a quiet footnote for Fried's 1966 essay, "Shape As Form: Frank Stella's Irregular Polygons," he even suggested (following Stanley Cavell) that high modernism had critical 'affinities' with Kuhn's paradigm shifts ${ }^{21}$ - which says a lot, considering the previous preamble on Harman's preoccupation with counterfactuals. In this sense, one could describe (heavily problematic as it may be) that Fried and Cavell posited high modernism as a mechanism for understanding the counterfactual sensuality of the avant-garde: a sort of, 'counterfactual' or "a paradigm shift of the senses."22 Any affinity has its problems, but to address Harman's rejection of materialism appropriately, engaging with high modernism might yield a different renegotiation on realist terms.

We might wish to reformulate the problems of 'the modernist conception of the medium' in aesthetic content, towards withdrawn autonomous things in reality: and moreover that every part of the work, has its own withdrawn autonomous reality within itself. Such a task would eschew intentionality, Fried's modernist hallmark of quality, in favour of a formalism that is nonmodern. ${ }^{23}$ There is no 'rightness' towards how a work is constructed, only that it is, and that it withdraws so monstrously from us, we can only but behold it. The artwork is more like a headless swarm or a computer program, than it is a modern transcendent experience: full of active, autonomous blind parts, that jostle within it contributing, but not holistically defining it. Each artwork and each variant of 
medium is different, yet also different from itself. If this is a formalism, then there is no 'right' way to suggest how an artist disrupts convention, or how an artist might determine all interpretations. Instead there is only the discontinuous change of novelty within different encounters of form, within form itself. In the same stretch OOO does not reduce such work to its material constituents, nor claim any 'right' way to make such work: only that there is one reality to the work, and it is withdrawn.

This brings me to another counterfactual: what if artists had not despised Fried after he wrote "Art and Objecthood" (1967)? Isn't there an interesting discussion to be had about the merits of Fried's analysis in light of Harman's rejection of materialism? Not that Fried was right of course, and he is certainly no realist.

It is a truism to suggest that almost no-one agreed with Fried's famous essay; or if they did, they agreed that his analysis was right, but his critical judgment wrong. Isn't Fried's rejection of literalism in Donald Judd and Robert Morris' minimalist objects, at least comparable to Harman's outright rejection of materialism? That the material, physical, immediate aspects of a work, cannot trump its autonomous individual effect? ${ }^{24}$ This is why in his essay "Frames of Reference" (2003) Jeff Wall stresses the importance of Fried's concern with Kantian illusionary finitude in the pictorial arts, both in painting and (much later) photography and (much, much later) video. ${ }^{25}$ Here's Wall:

I read "Art and Objecthood" to say that if an artwork simply cast its lot with physicality and immediacy, it lost its essential possibility as serious art and was reduced to a repetitious staging of the encounter between an object or group of objects in the world and a person looking at that object. It soon became obvious that it was arbitrary what the object was ... Fried showed that illusion is essential. ${ }^{26}$

This illusion was central to Fried's criticism of minimalism and how he co-implicated the connected term theatricality. Theatricality operates when illusion is suspended, or cut short, when the barrier between beholder and object is removed, and is no longer subject to naiveté. And this is why Judd's specific objects eliminated any sensual effect of sincerity: for they are ultimately hollow geometric shapes. The power of signification in traditional painting required elimination. As J. M. Bernstein accurately put it, Judd's objects:

[...] no longer depend for its holding in the visual field through anthropomorphic assumptions, but literally appear as an object, a mere thing, in the same 
way that natural objects appear for the natural scientist as constituted through quantities that escape the vagaries of human perceivings and doings. Judd wishes to achieve for artworks an analogue of the perspectiveless appearing that is the telos of absolute knowing: a view from nowhere. ${ }^{27}$

Judd cannot utterly remove the beholder from the work, but he can aspire to neutralise both by rendering them as pure surface and pure material. The beholder's situation generates the work, but it does so by eliminating the fullness of the object. The discrete activity of the work itself becomes more unnecessary, instead foregrounding the activity of a durative field than an emphasis on the presence of a work. This is what Pamela M. Lee termed chronophobia: an effect which she has chastised Fried for. ${ }^{28}$ Minimalism in Fried's eyes, becomes "inexhaustible ... not because of any fullness - that is the inexhaustibility of art - but because there is nothing there to exhaust, it is endless the way a road might be: if it were circular, for example." ${ }^{29}$ Or as Bernstein puts it so wonderfully again:

[... minimalist works create what might be termed "the art effect" without anything substantial corresponding to that effectivity ... If the sense of such works is the situation they compose, then they are not separate or independent from the viewer, and they are relational: poles or elements of a relational situation. Being only elements of a situation, deriving their identity from the situation they create, minimalist works lack any "in-side," any internal complexity or depth that would token their separateness or autonomy ... They simulate the manner of an aesthetic encounter without there being anything of significance to encounter. ${ }^{30}$

This 'in-side', an encounter with formal depth, or internal complexity, may have an important analogous conflict between Harman's realism of formal depth, against the materialist surface of an invisible, yet knowable, framework that generates such encounters. At the end of his article, Harman suggests that the form of any aesthetic content must be found in the mimetic involvement of the spectator or beholder and that their involvement as a real object is intrinsically required, so as to perform the unification of the sensual phenomena we are held by (in his case Ortega's cypress and the flame).

At first blush, this seems to ruin my Friedian account, by suggesting that only the theatrical performative presence of the spectator must compose the work in order to provide that medium. That is a fair charge, but at this stage the question is open. Isn't it exactly Harman's reliance on sincerity and quality which is at issue here? Fried clearly is aware that the beholder's illusion needs to be involved in the work, but such an 
involvement arises from the work's autonomous mechanism whose original autonomy cajoles sincerity out of them, rather than generating it. A nonmodern formalism is only interested in actors which are present for another actor's autonomy: and that such acting operates regardless of that object. Following Wall, illusion is central, not just for formal change, but for causal change.

Unlike Fried, Harman's suggestion that the formal aspects of an artwork are inaccessible, strikes me as a decent springboard to rejuvenate form in the present of today, and revise (or at least attempt to revise) previous understandings: in particular the unwarranted view (in my opinion) that being a formalist brings with it a sense of authority, mastery and knowledge. Formalism isn't about the 'rightness' of interpretation, but the miscommunicative contingencies of formal encounter.

\section{Notes}

1. Ian Bogost, Alien Phenomenology: Or, What It's Like to be a Thing (Minneapolis: University of Minnesota Press, 2012), 40.

2. See Thomas Kuhn, The Structure of Scientific Revolutions (Chicago: University of Chicago Press, 1962).

3. Graham Harman, "The Current State of Speculative Realism," Speculations IV (2013), 22-28; 27.

4. For Barbour's first article advancing the redundancy of time see Julian Barbour, "The Emergence of Time and Its Arrow from Timelessness," in Physical Origins of Time Asymmetry, eds. J.J. Halliwell, J. Pérez-Mercader, and W.H. Zurek (Cambridge: Cambridge University Press, 1994), 405-14. Here he introduces the "heap hypothesis" which raises similar affinities to Harman's objects: "I use the word heap," Barbour states, "because the individual objects in a heap are entities in their own right. They can be picked up and examined and have an intrinsic structure which exists independently of the fact that they belong in the heap." Ibid., 409.

5. Julian Barbour, The End of Time: The Next Revolution in Physics (Oxford: Oxford University Press, 1999), 16.

6. Ernst Mach, The Science of Mechanics: A Critical and Historical Account of Its Development, trans. Thomas J. McCormack (Chicago: The Open Court Publishing Company, 1919), 247.

7. Ernst Mach, The Science of Mechanics, 247.

8. See Peter Gratton and Michael Austin, Speculative Realism: An Introduction (London: Bloomsbury, 2014).

9. See Martin Hägglund, Radical Atheism: Derrida and the Time of Life (Stanford: Stanford University Press, 2008). 
10. Jane Bennett, "Systems and Things: A Response to Graham Harman and Timothy Morton," New Literary History 43 (Spring 2012): 225-33; 227.

11. Nicolas Bourriaud, Relational Aesthetics, trans. Simon Pleasance, Fronza Woods and Mathiew Copeland (Dijon: Les Presses Du Réel, 2002), 18.

12. Nicolas Bourriaud, Relational Aesthetics, 19 (author's emphasis).

13. Claire Bishop, "Antagonism and Relational Aesthetics," October, no. 110 (Fall 2004): 51-79.

14. See Grant H. Kester's discussion on Navjot Altaf's work "Nelpar" in Grant H. Kester, The One and the Many: Contemporary Collaborative Art in a Global Context (Durham: Duke University Press, 2011), 82-83.

15. See Charlie Gere and Michael Corris, Non-Relational Aesthetics (London: Artswords Press, 2008).

16. Rikke Hansen, "Things vs. Objects: Rikke Hansen on the Public Life of Things," Art Monthly, no. 318 (2008), http://www.artmonthly.co.uk/magazine/ site/article/things-v-objects-by-rikke-hansen-jul-aug-2008.

17. Carolyn Christov-Bakargiev, "Artistic Director's Statement," Introduction to Dokumenta (13) - Press Release, http://d13.documenta.de/uploads/tx_presssection/3_Introduction.pdf, Daniel Birnbaum, "Documenta 13," Artforum (October 2012), http://blog.urbanomic.com/sphaleotas/archives/id_34514/id_34514.htm.

18. Although it must be said that in a talk, entitled "Taste" at Western Michigan University, which took place on January 18th, 1983, Greenberg made a careful remark that he was misunderstood in defining the modernist program of "purity," put in scare quotes, not that he blamed those who misunderstood him. Instead of a militant formalist program, that condemned what artists should be doing, Greenberg insisted it was more of a description rather than an authoritative demand. Quoting Greenberg:

"I wrote a piece called "Modernist Painting" that got taken as a program when it was only a description, and I was thought to believe in things that I was describing [as a program]. Again, it was the fault of my rhetoric. I was in favor of "pure" art in spite of the fact that I put quotation marks around "pure" or "purity" whenever I used them, because I don't believe there's any such thing as pure art. It was an illusion. [...] There is no such thing as pure art, or pure poetry, or pure music. Anyhow I don't believe there is such a thing. But I made the mistake of contenting myself with quotation marks and not saying "look, I don't believe this as a program, I'm simply describing." And so people assumed that was my program. I'd been describing what I thought had happened under modernism, and nothing more and nothing less. It was also inferred that I had said there was some necessity working in this although I said nothing to that effect. But I blame myself. I should have been more careful." Clement Greenberg, "Taste," Transcript of a lecture given at Western Michigan University, January 18th, 1983. http:// 


\section{Robert Jackson}

www.sharecom.ca/greenberg/taste.html.

19. Michael Fried, Four Honest Outlaws (Cambridge: Harvard University Press, 2011), 8.

20. Michael Fried, "How Modernism Works: A Response to T. J. Clark," in Pollock and After: The Critical Debate, edited by Francis Frascin (New York: Harper and Row, 1985), 70.

21. Michael Fried, "Shape as Form: Frank Stella's Irregular Polygons," in Art and Objecthood (Chicago: University of Chicago Press, 2004), 99n11, cf. 77-99.

22. Note here that 'allure', one of Harman's categories for the aesthetic understanding of withdrawn objects is understood as a feature of Kuhn's counterfactual paradigm shifts, where "[a] paradigm is not an arbitrary principle constructed by a social community in a contingent time and place and imposed by the power of the mob, but rather the rule of a unified scientific object beyond all nail-filing arguments and contradictory evidence and public cataloguing of its traits ... 'Normal science,' like normal perception, tidies up our lists of known properties and fixes previous inconsistencies in our map of things, but does nothing to shift the underlying field of objects that are accepted as real. Allure, with its severing of objects and qualities, is the paradigm shift of the senses." See Graham Harman, Guerrilla Metaphysics: Phenomenology and the Carpentry of Things, (Chicago: Open Court, 2005), 152 (original emphasis).

23. See Bruno Latour, We Have Never Been Modern, trans. Catherine Porter (Cambridge: Harvard University Press, 1993), 78.

24. See Michael Fried, "Art and Objecthood," Artforum, no. 5 (June 1967), 1223. Reprinted in Minimal Art: A Critical Anthology, edited by Gregory Battcock (Berkeley: University of California Press, 1995), 116-47; Aesthetics: A Critical Anthology, edited by George Dickie and Richard J. Sclafani (New York: St Martins Press, 1977), 438-60 and Looking Critically: 21 Years of Artforum edited by Amy Baker Sandback (Ann Arbor: UMI Research Press, 1984), 61-68. Subsequent citations are taken from Art in Theory 1900-1990: An Anthology of Changing Ideas, edited by Charles Harrison and Paul Wood (Oxford: Blackwell, 1992), 822-34.

25. Michael Fried, Four Honest Outlaws, 171-76.

26. Jeff Wall, "Frames of Reference," in Selected Essays and Interviews (New York: The Museum of Modern Art, 2007), 178.

27. J. M. Bernstein, Against Voluptuous Bodies: Late Modernism and the Meaning of Painting (Stanford: Stanford University Press, 2006), 128.

28. Pamela M. Lee, Chronophobia: On Time in the Art of the 1960s (Cambridge, Mass.: MIT Press, 2006)

29. Michael Fried, "Art and Objecthood," 831.

30. J. M. Bernstein, Against Voluptuous Bodies, 133 (my emphasis). 